\title{
Aplicação da vulnerabilidade ambiental do município de Moju, estado do Pará
}

O município de Moju no Estado do Pará pertencente à Mesorregião do Nordeste Paraense e à Microrregião Tomé-Açu e está inserido no chamado 'polo biodiesel' que, atualmente, vivência uma fase de intensos investimentos agroindustriais de produção de óleo de palma visando suprir o mercado nacional e internacional de biocombustíveis. O município possui o menor percentual de áreas protegidas na sua mesorregião, vive com uma expansão da cultura de dendê, do polo biodiesel e o embargo das atividades do Município Verdes pela alta taxa de desmatamento e focos de calor, chamando a atenção para estudos ambientais. Neste contexto, o presente trabalho apresenta uma comparação e análise das influências das variáveis ambientais na determinação da vulnerabilidade ambiental do município de Moju. Através de Sistemas de Informações Geográficas, associou-se diversos graus de suscetibilidade das classes das variáveis. Com a ponderação Fuzzy, realizouse a sobreposição ponderada dos planos de informação referentes ao solo, geologia, cobertura vegetal e uso e ocupação do solo. Esta comparação permitiu determinar a fragilidade ou resiliência natural dos mesmos aos processos de degradação ambiental e ação antrópica e as influências de cada uma na determinação das diferentes vulnerabilidades ambientais. As comparações e análises realizadas procuraram determinar o quanto cada uma destas variáveis e suas respectivas classes contribuem para se estabelecer o grau de vulnerabilidade do município estudado.

Palavras-chave: Vulnerabilidade Ambiental; Lógica Fuzzy: Sistemas de Informações Geográficas (SIG).

\section{Application of the environmental vulnerability of the Moju municipality, state of Pará}

\begin{abstract}
The municipality of Moju in the State of Pará, belonging to the mesoregion of the Northeast of Pará and the Tomé-Açu microregion, is part of the so-called "biodiesel pole", which is currently experiencing a phase of intense agro industrial investments in the production of palm oil to supply the market national and international biofuels. The municipality has the lowest percentage of protected areas in its mesoregion, lives with an expansion of the palm oil crop, biodiesel pole and the embargo of the activities of the Municipality Greens due to the high rate of deforestation and heat sources, calling attention to environmental studies. In this context, the present work presents a comparison and analysis of the influences of the environmental variables in the determination of the environmental vulnerability of the municipality of Moju. Through Geographical Information Systems, several degrees of susceptibility of the variable classes were associated. With the Fuzzy weighting, we carried out the weighted overlap of information plans regarding soil, geology, vegetation covers and land use and occupation. This comparison allowed to determine the natural fragility or resilience of the same to the processes of environmental degradation and anthropic action and the influences of each one in the determination of the different environmental vulnerabilities. The comparisons and analyzes made sought to determine how each of these variables and their respective classes contribute to establish the degree of vulnerability of the municipality studied.
\end{abstract}

Keywords: Environmental Vulnerability; Fuzzy Logic; Geographic Information Systems (GIS).

Topic: Desenvolvimento, Sustentabilidade e Meio Ambiente

Reviewed anonymously in the process of blind peer.
Received: 10/06/2018 Approved: 24/07/2018
Leoni de Souza Belato (iD)

Instituto Tecnológico Vale, Brasil

http://lattes.cnpq.br/7063630868527586

http://orcid.org/0000-0002-9230-2246

leonibelato@gmail.com

Sérgio Luis Cardoso Serrã (10

Instituto Tecnológico Vale, Brasil

http://lattes.cnpq.br/7255962059886608

http://orcid.org/0000-0002-0803-2627

seuserrao@gmail.com

Amanda Lorenna Feio Gandra (D)

Instituto Tecnológico Vale, Brasil

http://lattes.cnpq.br/7379950905410403

http://orcid.org/0000-0002-7134-9651

amandagandra.337@gmail.com

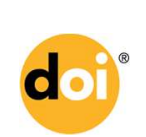

DOI: 10.6008/CBPC2179-6858.2018.005.0020

\begin{abstract}
Islia Lima de Sousa Amorim (iD)
Universidade do Estado do Pará, Brasil

http://lattes.cnpq.br/2161191307542899

http://orcid.org/0000-0001-6629-5794

islia.amorimeng@gmail.com
\end{abstract}

\section{Referencing this:}

BELATO, L. S.; SERRÃ, S. L. C.; GANDRA, A. L. F.; AMORIM, I. L. S.. Aplicação da vulnerabilidade ambiental do município de Moju, estado do Pará. Revista Ibero Americana de Ciências Ambientais, v.9, n.5, p.218-230, 2018. DOI: http://doi.org/10.6008/CBPC2179$\underline{6858.2018 .005 .0020}$ 


\section{INTRODUÇÃO}

Na microrregião de Tomé-Açu inicialmente a 'dendeicultura' enraizou-se nos municípios de Moju, foco desse estudo, Acará e Tailândia hegemonizada pelo Grupo Agropalma, atuante no segmento agroindustrial na região desde 1982, quando constituiu a primeira empresa denominada Companhia Real Agroindustrial S.A (CRAI) para desenvolver um projeto de cultivo de palma e extração de óleo de palma e óleo de palmiste em uma área de cinco mil hectares no município de Tailândia (NAHUM et al., 2012).

Conforme realizado o levantamento pela Embrapa (2006), verificou-se na área total do Pará, 124.804.200ha, mais de 5.500.000 ha em condições edafoclimáticas aptos para a implantação da cultura do dendezeiro. Essas áreas estão situadas nas microrregiões de Almerim, Portel, Furos de Breves, Arari, Belém, Castanhal, Bragantina, Cametá e Tomé-Açu, no qual o município de Moju está inserido. No Pará, segundo Cruz (2006), em função da localização das plantações e usinas de beneficiamento de dendê, distinguem-se dois polos de desenvolvimento do agronegócio. Um dos polos abrange os municípios de Tailândia, Moju e Acará, situados ao sul de Belém. O outro polo compreende os municípios de Benevides, Santa Izabel do Pará, Santo Antônio do Tauá, Castanhal, Igarapé-Açu e São Domingos do Capim, situados no Nordeste Paraense (NAHUM et al., 2012).

Atualmente, os municípios inseridos no 'polo biodiesel', com destaque para o município de Moju, vivem uma fase de intensos investimentos agroindustriais de produção de óleo de palma visando suprir o mercado nacional e internacional de biocombustíveis. Assim, surge o questionamento se esses municípios paraenses estariam preparados para receber uma política pública como essa que se configura em novas territorialidades e novas dinâmicas econômicas e ecológicas (HOMMA et al., 2012), e traz desafios para monitorar a expansão do cultivo do dendezeiro, que requer uma capacidade de gestão ambiental consistente (CARDOSO et al., 2014).

O conceito de vulnerabilidade é polissêmico e multiescalar e pode ser aplicado a diversas áreas do conhecimento, como a dimensão ambiental. Em países com susceptibilidade de ocorrências de fenômenos naturais, meteorológicos e geológicos, a vulnerabilidade ambiental tem o objetivo de avaliar os fenômenos naturais que são potenciais a causar desastres sociais, de outro modo existe a relação entre os problemas ambientais de procedência antrópica. Nessa perspectiva, utilizaram-se os princípios da Ecodinâmica e da Morfodinâmica, que enfocam as relações mútuas entre os diversos componentes do meio ambiente e têm por objetivo a gestão ambiental (SANTOS, 2015).

Mesmo sendo o município de maior extensão territorial da Região Integradora do Tocantins, Moju apresenta o menor percentual de áreas protegidas, somente 0,95\% de sua área total. O município reduziu para 43,10 km² o índice de desmatamento em 2011, em comparação ao índice em 2001 que era de 562,80 $\mathrm{Km}^{2}$, verifica-se uma redução de mais de $90 \%$, porém, mesmo com esse valor considerável, Moju continuou a ser o município que mais desmatou na Região de Integração do Tocantins no ano de 2011. Esse fato explica a alta incidência de focos de calor no município em questão, que chegou ao máximo de 920 focos em 2009 (IDESP, 2013). 
O alto índice de desmatamento no município fez com que suas atividades produtivas fossem embargadas, devido estar inserido no programa Municípios Verdes na classe municípios embargados, e não estar realizando atividades que condigam com os princípios básicos do programa. Até 2011, o município ainda não apresentava uma Secretaria Municipal de Meio Ambiente (IDESP, 2011). O município possui Conselho de Meio Ambiente, com caráter deliberativo, consultivo, normativo e fiscalizador. É o segundo município da Região de Integração do Tocantins com maior efetivo atuando na área ambiental, totalizando cerca de 53 pessoas (IDESP, 2013).

O momento que o município vive com uma expansão da cultura de dendê, o polo biodiesel e o embargo das atividades do Município Verdes pela alta taxa de desmatamento e focos de calor, chamam a atenção para estudos ambientais em Moju. Assim, este estudo objetivou analisar a vulnerabilidade ambiental no município de Moju, pertencente à Mesorregião do Nordeste Paraense e à Microrregião de Tomé-Açu, através da obtenção de dados que especializam os indicadores: geologia, solos, uso e ocupação do solo e vegetação no território municipal para posteriormente aplicar a Ponderação Fuzzy aos indicadores escolhidos, obter o mapa de vulnerabilidade ambiental, através da média aritmética entre rasters dos indicadores no software $\operatorname{ArcGis}^{\circledR} 10.1$ (ESRI) e identificar áreas que apresentem maior ou menor vulnerabilidade ambiental.

\section{REVISÃO TEÓRICA}

\section{Vulnerabilidade ambiental}

Para que se consiga estabelecer uma gestão eficiente sobre as atividades antrópicas que impactam direta ou indiretamente o solo e assim todo o ambiente que dele depende, é necessário estudar os seus aspectos dinâmicos e criar ferramentas que indiquem os níveis desses impactos. Assim como Tricart (1977) destacou:

Estudar a organização do espaço é determinar como uma ação se insere na dinâmica natural, para corrigir certos aspectos desfavoráveis e para facilitar a exploração dos recursos ecológicos que o meio oferece.

A dinâmica supracitada é resultado das relações entre os processos naturais e suas ações sobre a superfície terrestre, onde, segundo Santos (2015), a morfodinâmica se desenvolve. As ações naturais de clima, topografia, solo, geologia e cobertura vegetal sobre essa superfície afetam diretamente suas características em grau de denudação do solo, processos erosivos, formação de vegetação e solos, encharcamento do solo e biodiversidade dos ecossistemas. As atividades humanas de uso e ocupação do solo podem acelerar e intensificar esses processos naturais sem que o ambiente esteja preparado para suportar tais modificações.

Portanto, a vulnerabilidade ambiental é caracterizada pela interação entre os fenômenos e características físicas naturais de uma determinada área com as diversas atividades antrópicas realizadas na mesma área. Granger et al. (2000) e Hilhorst (2004) afirmam que a vulnerabilidade engloba a análise conjunta dos paradigmas físicos, estruturais e sociais e seus impactos sobre a superfície terrestre local. 


\section{Lógica Fuzzy}

A lógica de ponderação Fuzzy é baseada na lógica tradicional booleana em que um determinado fator recebe um valor em relação a sua existência/influência num fenômeno. A lógica booleana coloca dois extremos: verdadeiro ou falso com valor iguais a 1 (um) e 0 (zero); entretanto, a lógica Fuzzy aplica valores parciais entre o intervalo de 1 e 0 (ZIMMERMANN, 1987).

Assim, a lógica Fuzzy se torna uma ferramenta capaz de converter para uma linguagem racional (computacional) informações naturais do meio, sem perder informações e relações importantes entre elas, através da aproximação dos valores com cada influência dos fatores no fenômeno (ZADEH et al., 1997; SILVA, 2005).

Quando adiciona-se detalhes (valores) graduais e relaciona-se as análises individuais, diminui-se as chances de erros ou perdas de informações que são extremamente importantes em estudos ambientais e mapeamentos, possibilitando uma identificação analítica da questão, conforme destaca Sui (1992). Esse detalhamento é necessário nos estudos ambientais por permitir a integração e o balanceamento entre dados e observações subjetivas (sociais, econômicas e ambientais) para a descrição dos fenômenos complexos naturais e/ou antropogênicos (SILVERT, 2000).

\section{Modelagem Ambiental - SIGs e ARCGIS}

Os Sistemas de Informações Geográficas (SIGs) são um conjunto de ferramentas computacionais que possibilitam a modelagem e geração de mapeamentos de fenômenos espaciais com a integração de diferentes dados de uma determinada área de estudo. Portanto, aprimoram estudos holísticos e em baseiam processos decisórios de planejamento público, por conseguir dar uma visão espacial, quali-quantitativa e sistêmica das situações daquele meio (LAURINI et al., 1992; MOTA, 2003).

O Sistema engloba instrumentos necessários para desenvolver operações e relações complexas entre as informações espaciais e numéricas fundamentais para o gerenciamento a longa distância dos recursos naturais, áreas e atividades antrópicas que Ihe forem inseridas. Segundo Mota (2003), o SIGs é capaz de realizar operações matemáticas e possui ferramentas espaciais para modelagem e simulações, como operações matemáticas entre os planos de informações e zonas de proteção ao redor de uma área, essenciais para embasar gerenciamentos de recursos hídricos, monitoramentos ambiental, planejamentos urbanos, políticas de uso e ocupação do solo, entre outros, com eficiência e rapidez em estudos volumosos de dados.

No caso de estudos ambientais, a superposição de mapas é uma ferramenta encontrada nos softwares de SIGs, como o $\operatorname{ArcGis}^{\circledR} 10.1$. (ESRI) usado neste estudo, que permite a elaboração de um mapa final a partir da compilação de dados (mapas, imagens, operações numéricas, atribuição de valores, etc.) integrados sobre diversos temas de uma mesma área geográfica, através da superposição de camadas em formato raster. Essa compilação de dados facilita o gerenciamento da área, com várias informações diversas correlacionando-se em uma mesma imagem (mapa), perfeito para análises ambientais como a vulnerabilidade. 
Essa possibilidade de identificação de diversas relações ambientais e fenômenos morfo-dinâmicos em uma mesma imagem é chamada de análise multicritério, segundo Guidicini et al. (1976). A identificação de eventos naturais ou intensificados pela ação antrópica necessita dessa análise, a exemplo as subsidência e susceptibilidade ambiental a rebaixamento volumétrico, deslocamentos de terra, acúmulos de água, deposição de sedimentos, entre outros.

Os softwares do SIGs não possuem ferramentas próprias para executarem Operações Fuzzy em mapas, essa deve ser realizada após a análise dos dados obtidos da área em estudos e inseridos manualmente com as ferramentas a disposição de maneira coesa para que não haja erros nas regiões equitativas em questões problemáticas, que, no caso do estudo de vulnerabilidade ambiental engloba os indicadores de vegetação, solo, geologia, litologia, declividade, entre outros possíveis. Miranda (2005) destaca que o uso de SIG em estudos sistemáticos ambientais contribui para o planejamento e monitoramento estratégicos de um território, delimitando áreas prioritárias para ações públicas.

\section{Álgebra de Mapas}

A Álgebra de Mapas é um método de união de informações a campos geográficos, empregado em ferramentas de SIG. O modelo consiste em interpolar imagens, mapas temáticos e modelos numéricos, atribuindo os valores a suas posições espaciais geográficas (TOMLIN, 1990, citado por BARBOSA, 1997).

Ou seja, para Medeiros et al. (2001), a álgebra de mapas é uma espacialização dos elementos geograficamente, selecionados e combinados os atributos (valores) dentro dos limites estabelecidos (relevo, solos, cobertura vegetal, etc.), promovendo a subdivisão do espaço geográfico em regiões equiproblemáticas.

Segundo Barbosa (1997), pelo menos em quatro grandes grupos de estudo ligados à área ambiental, esse modelo por ser de implementado com grande utilidade na complementação dos Sistemas de Informação Geográficas: Mapeamento Temático, Diagnóstico Ambiental, Avaliação de Impacto Ambiental, Ordenamento Territorial e os Prognósticos Ambientais.

\section{MATERIAIS E MÉTODOS}

\section{Área de estudo}

O município de Moju pertence à Mesorregião do Nordeste Paraense, formada por 49 municípios e subdividida em 05 microrregiões (Bragantina, Cametá, Guamá, Salgado e Tomé-Açu), estando Moju localizado na microrregião de Tomé-Açu, demonstrado na Figura 1. A sede municipal apresenta as seguintes coordenadas geográficas 01 53' 10" de latitude Sul do Equador e 48 46' 00" de longitude a Oeste de Greenwich. Possuindo como limite ao norte os municípios de Abaetetuba e Barcarena, a leste os municípios de Acará e Tailândia, ao sul o município de Breu Branco e a oeste os municípios de Baião, Mocajuba e IgarapéMiri. (IDESP, 2014). 

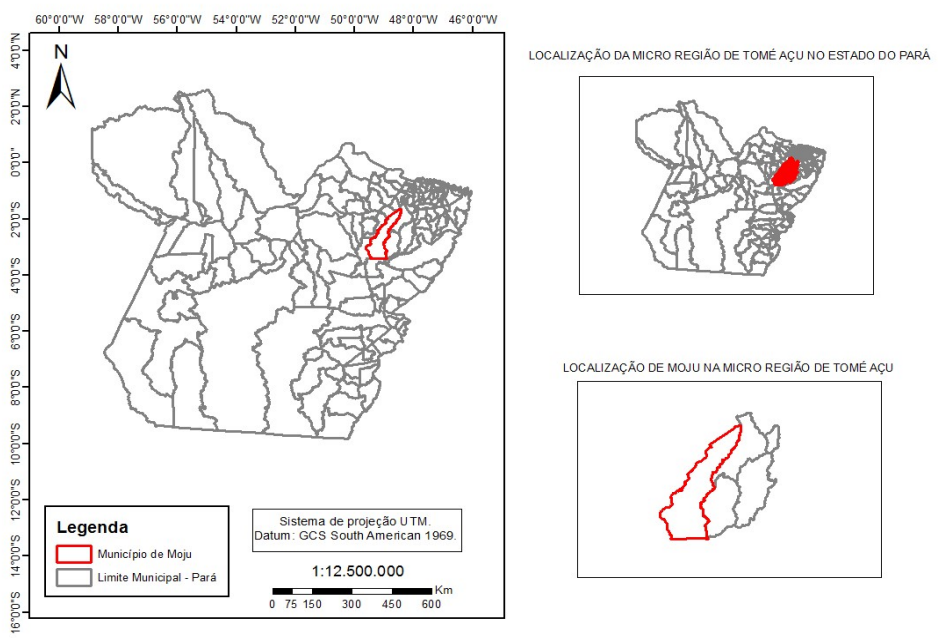

Figura 1: Localização espacial do município de Moju. Fonte: Censo Demográfico. IBGE (2010).

O município possui território aproximado de $9.093,85 \mathrm{Km}^{2}$ e densidade demográfica de cerca de $7,70 \mathrm{hab} / \mathrm{km}^{2}$, superior à média paraense (Figura 2). O rendimento médio mensal por habitante é de R\$ 178,23 (Figura 2). A expectativa de vida no município é de 67,85 anos. Em 2010, Moju ultrapassou as taxas estadual $(21,50)$ e nacional $(16,00)$ de mortalidade infantil, atingindo cerca de 26,25 para cada 1000 nascidos vivos. (IDESP, 2013).
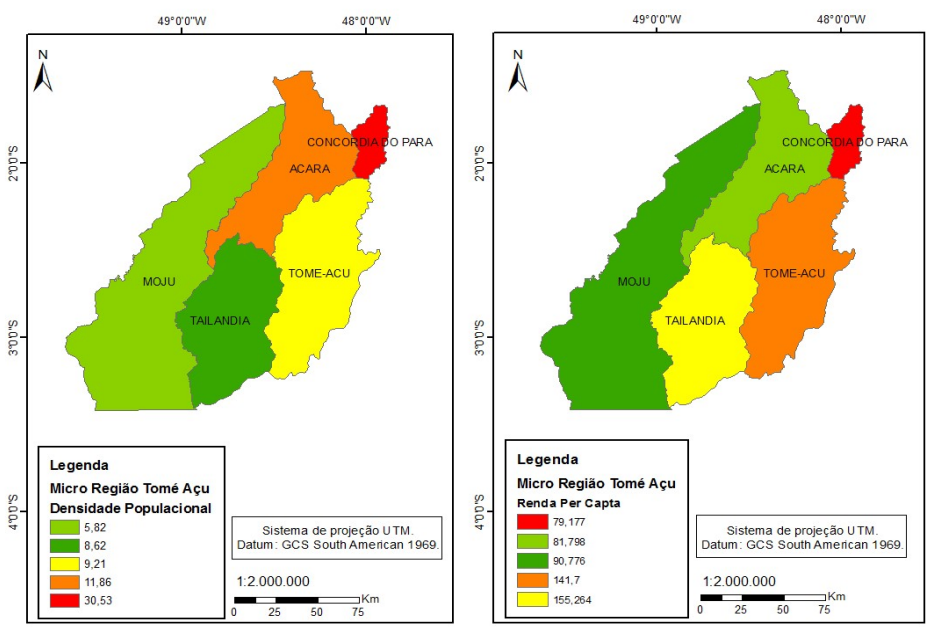

Figura 2: Densidade populacional da Microrregião de Tomé-Açu. Fonte: Censo Demográfico. IBGE (2010).

\section{Coleta de dados}

Neste trabalho, foi utilizado o recorte municipal para coincidir com as informações levantadas do município de Moju. As coletas de dados foram obtidas através do banco de dados disponíveis no site do Instituto Brasileiro de Geografia e Estatística (IBGE - Censo 2010), onde foram obtidos dados sobre os aspectos do município que envolvem sua caracterização geológica, densidade populacional, renda per capta e os limites municipais do estado do Pará. Os dados referentes à vegetação e solos foram obtidos através do banco de dados do Ministério do Meio Ambiente (MMA - i3Geo) e para o uso e ocupação do solo os dados foram obtidos através do projeto TerraClass (INPE). 


\section{Análise de dados}

A delimitação municipal foi escolhida pelos autores por facilitar o levantamento de dados socioeconômicos a partir das estatísticas municipais e por setores censitários, coletados no (IBGE), que podem ser considerados na análise de vulnerabilidade ambiental do local. Outra justificativa refere-se ao fato de tratar-se de uma delimitação territorial administrativa e pode contribuir para o planejamento e gestão ambiental municipal, através da análise da vulnerabilidade ambiental municipal.

Os indicadores ambientais a serem analisados conforme suas características são: geologia, solos, vegetação e cobertura e uso do solo. Serão utilizados para determinar a fragilidade ou resiliência natural da compilação desses indicadores aos processos de degradação ambiental municipais. A primeira etapa da metodologia consistiu na obtenção de dados para serem espacializados nos mapas dos indicadores escolhidos. Após a aquisição dos dados os mesmos foram plotados no programa ArcGis ${ }^{\circledR} 10.1$. (ESRI) para que fosse realizado o seu processamento. Após o processamento dos dados, que consistiu basicamente em recortes, de tal forma que somente os valores relevantes e relativos ao município de estudo fossem espacializados, foi realizada a ponderação Fuzzy nos mesmos.

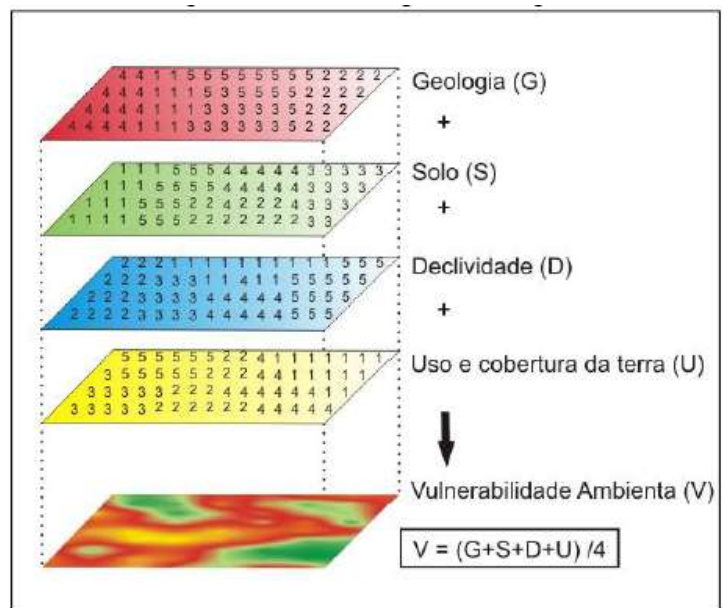

Figura 3: Modelo de álgebra de mapas para vulnerabilidade ambiental. Fonte: DIAS (2012)

Quadro 1: Resumo das etapas da metodologia.

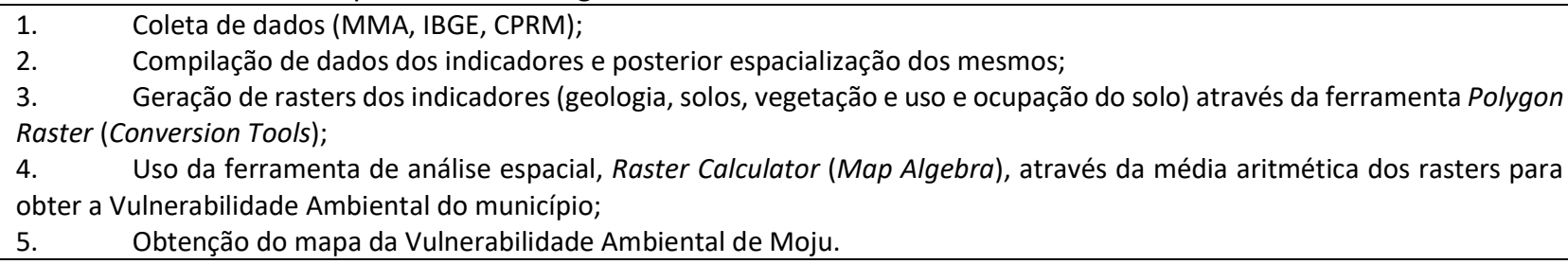

A ponderação Fuzzy foi a segunda etapa da metodologia que consiste em atribuir valores no intervalo de $[0,1]$ para os indicadores, conforme critérios previamente estabelecidos após a obtenção dos mapas dos indicadores, próximos de zero para fatores que pouco influenciam na vulnerabilidade e próximos de um para os que mais influenciam.. Essa atribuição foi feita na própria tabela de atributos de cada indicador no programa ArcGis ${ }^{\circledR}$ 10.1. (ESRI), através da inserção de uma nova coluna intitulada 'Ponderação_Fuzzy_Nome 
do Indicador', antes de transformá-los em formatos vetoriais (raster), formato no qual realizou-se os cálculos de vulnerabilidade ambiental. Os mapas de ponderação apresentam as áreas com menor resistência a fatores degradantes nas cores laranja e vermelho, áreas amarelas com resistência média e áreas com menor vulnerabilidade ambiental, em tons de verde.

Para gerar o mapa de vulnerabilidade ambiental, utilizou-se o modelo de álgebra de mapas (Figura 3), onde houve o cruzamento dos valores de Ponderação Fuzzy de cada indicador (geologia, solos, uso e ocupação do solo e vegetação) em formato de rasters, no software $\operatorname{ArcGis}^{\circledR}$ 10.1. (ESRI). A compilação dos rasters de indicadores gerados foi feita através da ferramenta raster calculator do pacote Spatial Analyst Tools, na forma de uma média aritmética entre os rasters gerados, conforme exemplificado acima e foi gerado o mapa da Vulnerabilidade Ambiental do município de Moju, especializado na Figura Y.

\section{RESULTADOS E DISCUSSÃO}

\section{Indicadores Ambientais}

Os indicadores ambientais são escolhidos criteriosamente por obterem informações capazes de construir, em conjunto, um cenário da situação de vulnerabilidade da área do município. Dentro de cada indicador escolhido (solo, geologia, vegetação e uso e ocupação do solo) existem os critérios ambientais a serem analisados e valorados. Os solos do município são representados pela classe dos Latossolos, tais como: Latossolo Amarelo, textura argilosa, e solos Concrecionários Lateríticos; Latossolo Amarelo, textura argilosa, e Latossolo Amarelo, textura média, além de Areias Quatzosas e solos Aluviais, conforme mostra a Figura 4 (IDESP, 2014).

A estrutura geológica e o tipo de relevo (considerado simplificado), são determinantes para que a topografia do município seja considerada de variação moderada. Embora o Município apresente cotas altimétricas próximas a 30 metros, sua sede está localizada a apenas 18 metros em relação ao nível do mar. A estrutura geológica dominante é representada por terrenos da Formação Barreiras, do período Terciário, e, em menor escala, por sedimentos do Quaternário Subatual e Recente (Figura 4) (IDESP, 2014).

A vegetação do município é representada pela Vegetação Densa de Planície Aluvial, nas áreas de várzea; pela Vegetação Secundária Latifoliada de terra firme e pela Floresta Densa dos baixos platôs e terraços (Figura 5) (IDESP, 2014). O município apresenta o clima do tipo mesotérmico e úmido. A temperatura média anual é elevada, girando em torno de 25ㅇ. C. Seu regime pluviométrico fica, geralmente, próximo dos $2.250 \mathrm{~mm}$. As chuvas, apesar de regulares, não se distribuem igualmente durante o ano. O período de janeiro a junho é o mais chuvoso, apresentando uma concentração de cerca de $80 \%$, implicando grandes excedentes hídricos e, consequentemente, grandes escoamentos superficiais e cheias dos rios. A umidade relativa do ar gira em torno de 85\% (IDESP, 2014). Não foi possível incluir o levantamento climático de Moju na metodologia aplicada, devido à falta de estações meteorológicas dentro dos limites municipais. 


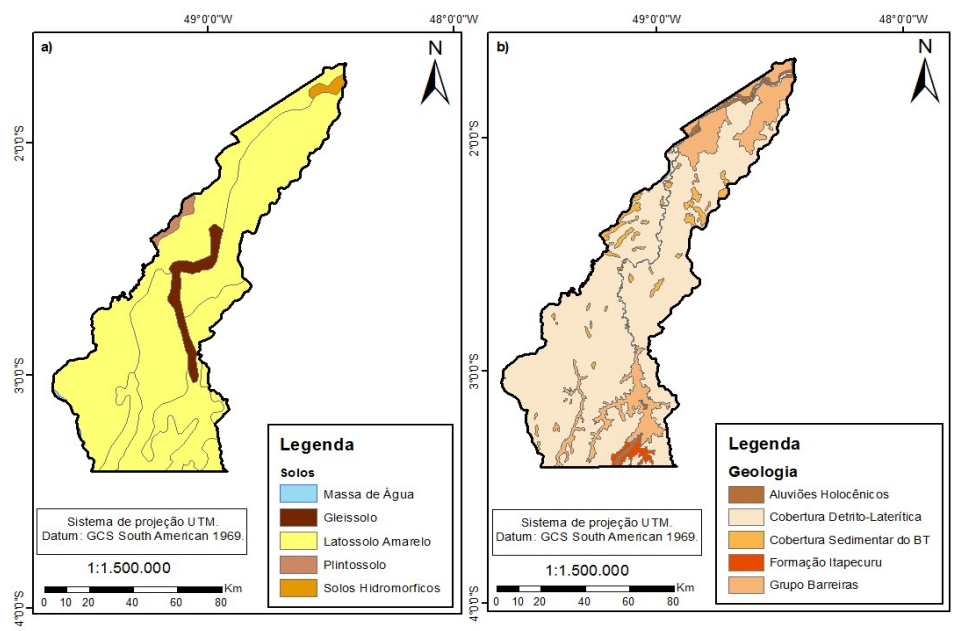

Figura 4: Mapa de solos e geologia do município de Moju. Fonte: a) i3Geo, MMA (2016); b) IBGE, 2010.

Hoje, o município possui uma expansão das atividades de dendê dentro do seu território, assim como tem sofrido influências do pólo de biocombustível, como dito anteriormente. O município possui uma grande porcentagem de área não antropizada, vulnerável a ações antrópicas impactantes, como o desmatamento, a pecuária por pasto e a agricultura que são fortes nas regiões rurais e periféricas.
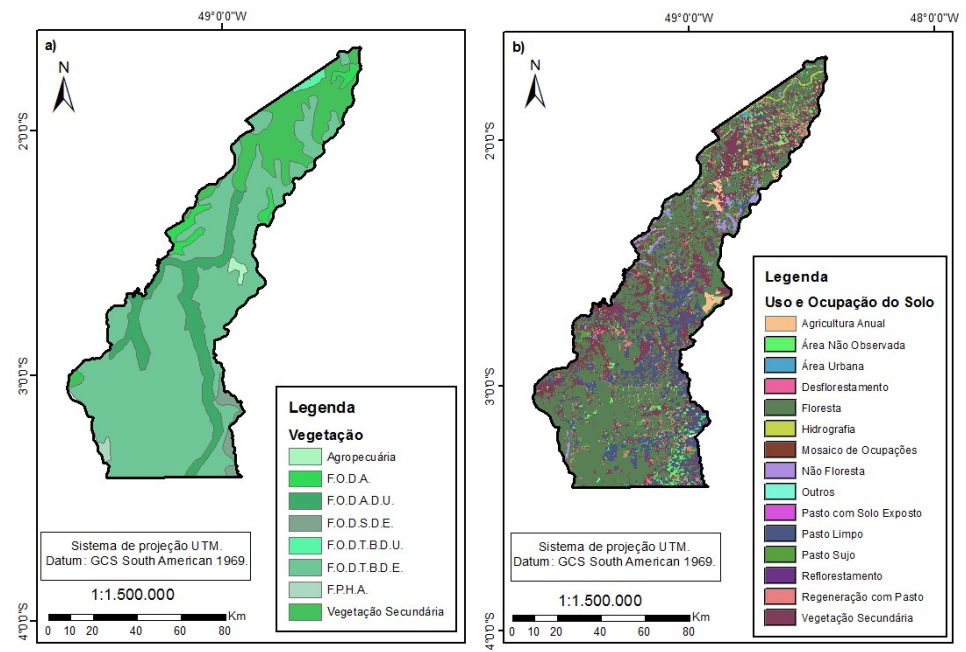

Figura 5: Mapa de vegetação e uso e ocupação do solo do município de Moju.

Fonte: a) i3Geo, MMA (2016); b) TerraClass (2016).

O rio Moju, que nasce em Rondon do Pará, banha o município de Moju à sudeste. Este rio é considerado um importante limitante territorial para o município, pela margem esquerda nos municípios de Baião, Mocajuba, Igarapé Miri e Abaetetuba, desaguando em Barcarena. Possui inúmeros afluentes em ambas as margens, sendo mais expressivos os que recebe pela margem esquerda, como os rios Cairari, Mamorama e Pirateua e pela margem direita, os afluentes mais importantes são o rio Ubá e os inúmeros igarapés da região (IDESP, 2014).

\section{Ponderação Fuzzy}

Cada classe de solo observados no território municipal de Moju, foi adotado um valor de acordo com sua composição (Tabela 1). Para solos mais inundados, valores maiores, devido a possibilidade de ocorrer 
fenômenos naturais negativos, como erosivos, ser maior, o que os torna menos resistentes. Os dados foram compilados conforme apresentados na Figura 6.

Atribuiu-se valores, no intervalo de 0 a 1, para cada formação geológica tendo como referência suas respectivas estruturas geológicas do município de Moju, através de dados do IBGE, conforme demonstrados na Tabela 1, para posterior formulação do mapa de Ponderação Fuzzy (Figura 6). Os valores foram atribuídos através da idade geológica das formações encontradas dentro dos limites territoriais do município. Sendo que, quanto mais antiga for a rocha, maior é a sua resistência a fatores degradantes, como erosão e assim, torna-se menos vulnerável (valores menores de vulnerabilidade).

Tabela 1: Ponderação Fuzzy: Solos e Geologia do município de Moju.

\begin{tabular}{|l|l|l|l|}
\hline Solos & Ponderação Fuzzy & Geologia & Ponderação Fuzzy \\
\hline Massa de Água & 0.9 & Aluviões Holocênicos & 0.5 \\
\hline Gleissolo & 0.8 & Cobertura Detrito-Laterítica Pleistocênica & 0.9 \\
\hline Latossolo Amarelo & 0.3 & Cobertura Sedimentar do BT & 0.8 \\
\hline Plintossolo & 0.5 & Formação Itapecuru & 0.6 \\
\hline Solos Hidromorficos & 0.9 & Grupo Barreiras & 0.9 \\
\hline
\end{tabular}

Fonte: Compilado de Santos (2015).
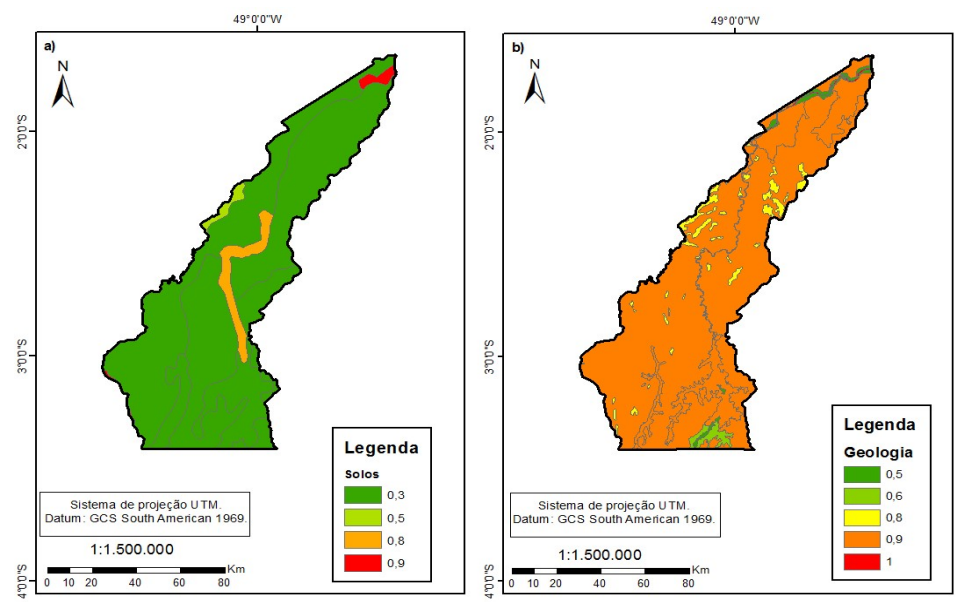

Figura 6: Ponderação Fuzzy: Solos e Geologia. Fonte: a) i3Geo, MMA (2016); b) IBGE, 2010.

Tabela 2: Ponderação Fuzzy: Vegetação e Uso e Ocupação do solo no município de Moju.

\begin{tabular}{|l|l|l|l|}
\hline Vegetação & Ponderação Fuzzy & Uso e Ocupação do Solo & Ponderação Fuzzy \\
\hline Agropecuária & 0.7 & Agricultura Anual & 0.7 \\
\hline F.O.D.A. & 0,2 & Área Não Observada & 0.1 \\
\hline F.O.D.A.D.U. & 0.1 & Área Urbana & 1.0 \\
\hline F.O.D.T.B.D.E. & 0.6 & Desflorestamento & 0.9 \\
\hline F.O.D.T.B.D.U. & 0.3 & Floresta & 0.1 \\
\hline F.O.D.S.D.E. & 0.7 & Hidrografia & 1.0 \\
\hline V.P.H.A. & 0.2 & Mosaico de Ocupações & 0.7 \\
\hline Vegetação Secundária & 0.4 & Não Floresta & 0.5 \\
\hline & & Outros & 0.5 \\
\hline & & P. S. E. & 0.9 \\
\hline & & Pasto Limpo & 0.7 \\
\hline & & Pasto Sujo & 0.8 \\
\hline & Reflorestamento & 0.3 \\
\hline & & R. P. & 0.3 \\
\hline & & Vegetação Secundária & 0.3 \\
\hline
\end{tabular}

Fonte: Compilado de Santos (2015).

Atribuiu-se valores para os intervalos de vegetação encontrados através de imagens do MMA, em sua plataforma i3Geo. Os intervalos dos tipos de vegetação do município foram classificados levando-se em 
consideração sua maior ou menor concentração de vegetação, já que quanto mais concentrada a vegetação, menor será o impacto de fatores externos ao solo, conforme demonstrados na Tabela 2 e Figura 7.

Sobre as atividades realizadas no município de Moju, os valores foram atribuídos em grau de degradação ambiental, baseando-se na relação de que áreas verdes ou florestadas devem possuir valores mais baixos, próximos de 0,1 e áreas que já sofreram algum tipo de degração valores mais altos, e próximos de 1, conforme observado nas Tabela 2 e Figura 7.
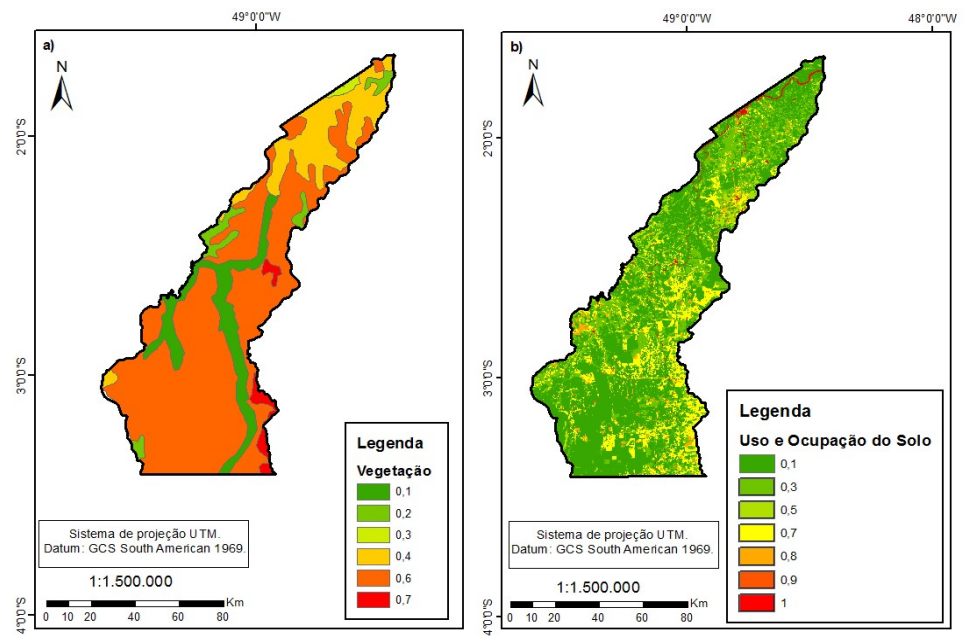

Figura 7: Ponderação Fuzzy: Vegetação e Uso e Ocupação do Solo. Fonte: a) i3Geo, MMA (2016); b) TerraClass (2016).

\section{Vulnerabilidade Ambiental}

Através da aplicação da metodologia apresentada foi obtido o mapa da Vulnerabilidade Ambiental do município de Moju, conforme apresentado na Figura 8, que sintetiza os valores de Ponderação Fuzzy de vulnerabilidade de cada indicador ambiental estabelecido. O mapa agrupa em cada intervalo de valores de vulnerabilidade, informações de todos os aspectos dos indicadores, não se trata de um simples cruzamento de dados, mas, da interrelação de análises dos fatores ambientais que influenciam na resistência física da área a atividades antrópicas e a fenômenos naturais degradantes.

Segundo Santos (2015), a baixa ou muito baixa vulnerabilidade, indicada por valores entre 0,00075 e 0,14 são influenciados com maior intensidade pelos indicadores: vegetação e uso e cobertura do solo. Há nessas áreas em tons de verde, a presença de florestas diversas, como a Floresta Ombrófila Densa Aluvial com Dossel Uniforme (F.O.D.A.D.U.), áreas de reflorestamento, regeneração por pasto e com vegetação secundária, ou seja, são compostas por coberturas de solo densas que diminuem os impactos de fatores externos ao seu meio ou áreas que estão sendo recuperadas e assim, reestabelecendo sua resistência. Essas áreas podem ser consideradas morfodinamicamente estáveis e que devem ser preservadas contra ações antrópicas degradantes, como o desmatamento, para que não sofram futuros danos.

As áreas de vulnerabilidade alta ou muito alta sofreram maior influência dos indicadores: geologia, solos e uso e cobertura do solo. As áreas, em vermelho, possuem características geológicas e de solo frágeis, onde são encontradas rochas recentes e solos muito inundados, características que são comuns em solos amazônicos, entretanto, as atividades antrópicas castigam essas áreas e diminuem sua resistência natura. Conforme foi colocado ao longo do trabalho e confirmado com o levantamento de dados, essas áreas 
possuem atividades de agricultura e pecuária intensas que impulsionam a retirada da cobertura vegetal natural, tanto com queimadas, quanto com a transformação delas em pastos e monoculturas. Esses impactos degradantes são ainda mais negativos, com a urbanização do interior do município.

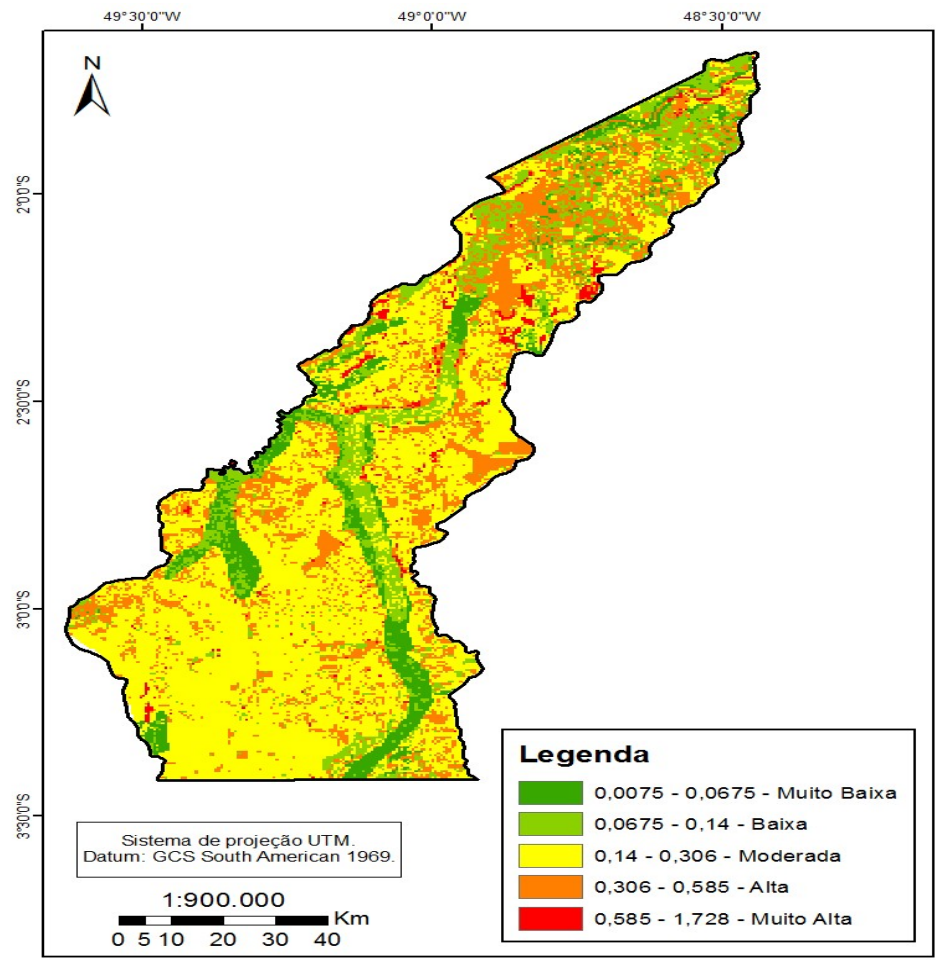

Figura 8: Vulnerabilidade Ambiental no município de Moju, PA. Fonte: i3Geo (MMA), IBGE e TerraClass.

As áreas de vulnerabilidade média, em amarelo, possuem formação geológica mais recente que a formações das áreas de alta vulnerabilidade. Essas faixas sofrem influência dos indicadores de vegetação e uso e cobertura do solo, onde são encontradas algumas florestas emergentes e são desenvolvidas atividades antrópicas diversas de médio impacto ambiental.

\section{CONCLUSÕES}

De acordo com o que foi abordado no seguinte trabalho, objetivando-se analisar a vulnerabilidade ambiental no município de Moju, estado do Pará, utilizou-se a Lógica Fuzzy para visualizar a sobreposição aritmética dos planos de informação referentes aos indicadores solo, geologia, uso e cobertura do solo e vegetação.

As comparações e análises apresentadas procuraram determinar o quanto cada uma destas variáveis e suas respectivas classes contribuem para se estabelecer o grau de vulnerabilidade do município de Moju e as áreas de vulnerabilidade alta ou muito alta, sofreram maiores influências dos indicadores: geologia, solos e uso e cobertura do solo, onde são encontradas rochas recentes e solos muito inundados, características que são comuns em solos amazônicos e alteram resistência natural do meio à vulnerabilidade.

As áreas de vulnerabilidade média estudadas possuem formação geológica mais antiga que a formações das áreas de alta e muito alta vulnerabilidade e essas faixas sofrem influências da vegetação, uso e cobertura do solo e essas áreas possuem atividades de agricultura e pecuária intensas que impulsionam a 
retirada da cobertura vegetal natural. As áreas com vulnerabilidades baixas ou muito baixas são regiões do município pouco antropizadas e que ainda possuem vegetação primária, ou seja, possuem um baixo risco de erosão e degradação ambiental.

\section{REFERÊNCIAS}

BARBOSA, C. C. F.. Álgebra de mapas e suas aplicações em sensoriamento remoto e geoprocessamento. 1997. $157 p$, (INPE-7115 TDI/667). Dissertação (Mestrado em Sensoriamento Remoto) - Instituto Nacional de Pesquisas Espaciais, São Jose dos Campos, 1997.

CARVALHO, R. P. B.; COSTA, V. C.. SIGS aplicados à identificação de áreas suscetíveis a subsidência po recalque: um estudo comparativo entre os programas Vista Saga e Arcgis na baixada de Jacarepaguá (Rio de Janeiro). Rio de Janeiro, 2015

DIAS, V. S. B.. Análise Hierárquica Processual (AHP) na Modelagem da Vulnerabilidade Ambiental do Mini corredor Ecológico Serra das Onças (BA). 2012.

\section{GUIDICINI, G.; NIEBLE, C. M.. Estabilidade de taludes} naturais e de escavação. São Paulo: Edgard Blucher, 1976.

IDESP. Instituto de Desenvolvimento Econômico Social e Ambiental do Pará. Perfil da gestão ambiental dos municípios paraenses: programa municípios verdes. Belém, 2011.

IDESP. Instituto de Desenvolvimento Econômico Social e Ambiental do Pará. Indicadores de qualidade ambiental dos municípios da Região de Integração Tocantins. Belém, 2013.

IDESP. Instituto de Desenvolvimento Econômico Social e Ambiental do Pará. Estatística Municipal: Moju. Belém, 2014.

LAURINI, R.; THOMPSON, D.. Fundamentals of Spatial Information Systems. Toronto: Academic Press, Longman, 1992.
MEDEIROS, J. S.; CÂMARA, G.. GIS para Estudos Ambientais. In: CÂMARA, G.; DAVIES, C. et al. Introdução à Ciência da Geoinformação. São José dos Campos: INPE, 2001.

MIRANDA, J. I.. Fundamentos de Sistemas de Informações Geográficas. Brasília: EMBRAPA, 2005.

MOTA, S.. Urbanização e meio ambiente. 3 ed. Rio de Janeiro: ABES, 2003.

NAHUM, J. S.; MALCHER, A. T. C.. Dinâmicas territoriais do espaço agrário na Amazônia: a dendeicultura na microrregião de Tomé-Açu (PA). CONFINS, n.16, 2012. DOI: http://doi.org/10.4000/confins.7947

SANTOS, P. S.. Estudo da vulnerabilidade ambiental no município de Santo Amaro-BA. Salvador, 2015.

SILVA, S. F.. Zoneamento Geoambiental com auxílio da lógica fuzzy e proposta de um geoindicador para caracterização do meio físico da bacia do rio do Peixe. São Carlos, 2005.

SUI, D. Z.. A fuzzy gis modeling approach for urban land evolution. Computer environment and urban systems, v.16, n.2, p.101-115, 1992.

ZADECH, L. A.; JAMSHIDI, M.; TITLI, A. BOVERIE, S. Aplications of fuzzy logic: Towards high machine intelligence quotient systems. Series on environmental and intelligent manufacturing. Prentice hall, 1997.

ZIMMERMANN, H. J.. Fuzzy sets, decision making, and expert systems. Boston: Kluwer Academic Publishers, 1987.

A CBPC - Companhia Brasileira de Produção Científica (CNPJ: 11.221.422/0001-03) detém os direitos materiais desta publicação. Os direitos referem-se à publicação do trabalho em qualquer parte do mundo, incluindo os direitos às renovações, expansões e disseminações da contribuição, bem como outros direitos subsidiários. Todos os trabalhos publicados eletronicamente poderão posteriormente ser publicados em coletâneas impressas sob coordenação da Sustenere Publishing, da Companhia Brasileira de Produção Científica e seus parceiros autorizados. Os (as) autores (as) preservam os direitos autorais, mas não têm permissão para a publicação da contribuição em outro meio, impresso ou digital, em português ou em tradução. 